Rhode Island College

Digital Commons @ RIC

$1-1-2014$

\title{
Educational Innovation Brief: Educating Graduate Nursing Students on Value Based Purchasing
}

Kristen M. Farrell

Rhode Island College

Follow this and additional works at: https://digitalcommons.ric.edu/etd

Part of the Other Education Commons, and the Public Health and Community Nursing Commons

\section{Recommended Citation}

Farrell, Kristen M., "Educational Innovation Brief: Educating Graduate Nursing Students on Value Based Purchasing" (2014). Master's Theses, Dissertations, Graduate Research and Major Papers Overview. 232. https://digitalcommons.ric.edu/etd/232

This Major Paper is brought to you for free and open access by the Master's Theses, Dissertations, Graduate Research and Major Papers at Digital Commons @ RIC. It has been accepted for inclusion in Master's Theses, Dissertations, Graduate Research and Major Papers Overview by an authorized administrator of Digital Commons @ RIC. For more information, please contact digitalcommons@ric.edu. 


\title{
EDUCATIONAL INNOVATION BRIEF:
}

EDUCATING GRADUATE NURSING STUDENTS ON VALUE BASED

\section{PURCHASING}

\author{
by \\ Kristen M. Farrell \\ A Major Paper Submitted in Partial Fulfillment \\ of the Requirements for the Degree of \\ Master of Science in Nursing \\ in
}

The School of Nursing

Rhode Island College

2014

This paper was submitted as an educational brief to The Journal of Nursing Education. 


\begin{abstract}
The Patient Protection and Affordable Care Act implemented value-based purchasing to raise the bar on quality care and patient satisfaction in healthcare facilities. The time has come to educate graduate nursing students on the reality of quality indicators and the impact that advanced practice nurses will have on these initiatives. This educational brief describes implementation of an educational session developed for graduate nursing students on VBP and the APN role. The content for the education was derived from an extensive literature review, The Essentials of Master's Education in Nursing, and the clinical experience of the author. The education was presented to 12 Master's in nursing students utilizing a presentation with a pre-/post-test, followed by a question and answer session. Pre/post test scores showed an average increase in mean score of 17 points. Students' enthusiasm indicated that the content would be of benefit to them as they transitioned to the APN role. Consistent with The Essentials of Master's Education in Nursing, specific to Essential III (Quality Improvement and Safety), it is recommended that current quality initiatives specific in the APN role be integrated into the curriculum.
\end{abstract}

\title{
Acknowledgments
}

I would like to acknowledge Judy Murphy Phd, RN, CNE and Cynthia Padula, Phd, RN CNS for all their guidance and collaboration in the development of this educational brief. 


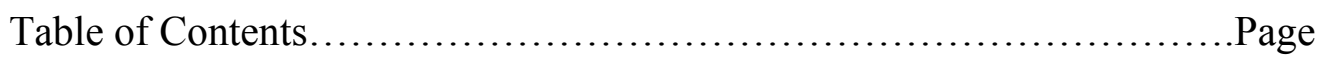

Introduction...................................................

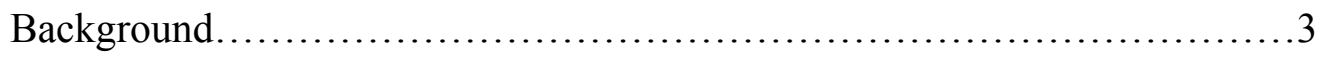

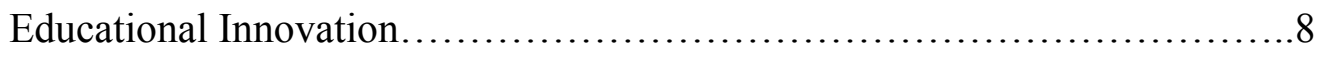

Discussion and Recommendations..................................... 11

Conclusion..................................................... 12

References................................................... 13 
Healthcare today is an ever changing industry. Facilities are facing more public reporting and pay for performance measures in regard to reimbursement. With the implementation of The Patient Protection and Affordable Care Act (PPAC) in 2010, the federal government is taking a closer look at healthcare. One key aspect of the PPAC focuses on the quality of care that is being delivered in hospitals. Hospital value-based purchasing (VBP) was implemented to raise the bar on quality care and patient satisfaction in healthcare facilities. The Centers of Medicare and Medicaid (CMS) may withhold 1\% of the annual $2 \%$ payment given to hospitals for fiscal year 2013, based on their VBP score. There are two current components that produce a VBP score for fiscal year 2013 (hcahpsonline, 2012, para 16). One evaluates 12 chosen CMS Core Measures from the current data elements of acute myocardial infarction, heart failure, pneumonia and the surgical care improvement project. The second evaluates components of the Hospital Consumer Assessment of Healthcare Providers and Systems (HCAHPS) survey, a nationally standardized tool, the results of which are publically reported. This 27 item survey was constructed to collect data about patients' perception of their hospital stay and is distributed randomly to inpatient discharges. Eight components of HCAHPS are reviewed for VBP including communication with nurses, communication with doctors, responsiveness of hospital staff, pain management, communication about medications, cleanliness and quietness of hospital environment, and discharge information; and one global item which is 
overall hospital rating (hcahpsonline, 2012, para 17).

As members and potential leaders of the health care team, advanced practice nurses (APNs) play an important role ensuring that patients achieve the best possible outcomes and are satisfied with their care. To accomplish this, APNs must be knowledgeable about contemporary quality initiatives. The revised The Essentials of Masters Education in Nursing (“The Essentials”) (American Association of Colleges of Nursing [AACN], 2011) reflects the expectation that Master's prepared nurses be educated about performance measures, culture of safety principles, and standards related to quality. The expectation in Essential III (Quality Improvement and Safety) is that graduate nurses be prepared to institute quality principles within an organization and be a change agent. The purpose of this project was to increase the knowledge of graduate nursing students in regard to value-based purchasing, which includes CMS Core Measures and HCAHPS, and the role of APNs in contributing to quality care and patient outcomes. 


\section{Background}

The Institute of Medicine defined healthcare quality as " the degree to which health services for individuals and populations increase the likelihood of desired health outcomes and are consistent with current professional knowledge" (IOM, 2001, para. 3). In 1996, the IOM released a report entitled America's Health in Transition: Protecting and Improving Quality that demonstrated a need to focus attention on and improve the quality of healthcare in America. The IOM initiated a three phase approach. The first phase documented the severe lack of quality in healthcare delivery. The second phase, from 1999-2001, published a vision of healthcare which was constructed by the Committee on Quality of Health Care in America: to improve quality care and bridge the gap between what was being practiced versus what is good quality care. During this time, the IOM released two reports, To Err is Human: Building a Safer Health Care System (1999) and Crossing the Quality Chasm: A New Health System for the 21st Century (2001), which further illustrated the inadequate quality of US healthcare and the need for reform. The third phase strives to operationalize a healthcare system as outlined in the Quality Chasm report. Reform of the US healthcare system requires a concerted effort involving clinicians, healthcare organizations, government agencies, and quality organizations. This collaborative effort guides reform by intersecting at three levels: the environmental level; the level of the health care organization; and the relationship between clinicians and patients (IOM, 2001). 
Quality measures used in data reporting and pay for performance must meet four criteria. First, the measure must be based on a strong foundation of research showing that the process addressed by the measure, when performed correctly, leads to improved clinical outcomes. Second, the measurement strategy must accurately capture whether evidencebased care has been delivered. Next, the measure should address a process proximate to the desired outcome, with relatively few intervening processes. Finally, the measure should have minimal or no unintended adverse consequences (Chassin, Loeb, Schmaltz \& Wachter., 2010). As quality of care and patient outcomes continue to move forward, these four criteria can be used to guide CMS and The Joint Commission (TJC) in developing accountability measures and ensuring evidence based practice. The Joint Commission and CMS have worked to align these measures to decrease the incidence of duplicate reporting while also recognizing that these measures need to be constantly evolving to stay in sync with emerging science. VBP is "any purchasing practice aimed at improving the value of health care services, where value is a function of both quality and cost" (AHRQ 2012, part 1, para 2). Centers for Medicare/Medicaid Services views VBP as a key component in refurbishing how care and services are paid for. Pay for participation alone in CMS initiatives is becoming a thing of the past (Medicare Program; Hospital Inpatient Value-Based Purchasing Program, Federal Register 2011). 
The VBP initiative includes evidence based practice and evaluates the patient experience; healthcare providers need continuous education so they are well-informed of quality initiatives that promote quality outcomes. With the increasing emphasis on quality, it is essential that all healthcare providers make this a priority. The essence of the VBP program is to provide evidence based care to patients, to promote them with the best outcomes, and ensure their experience is satisfactory. Value based purchasing is not a stagnant program but one that continues to evolve every fiscal year, accumulating more initiatives and increasing the risk of potentially having a negative effect on reimbursement. The intended benefits of VBP are still undetermined. Eldridge and Korda (2011) focused on what works with VBP and if it will improve health outcomes or reduce healthcare costs. The study design was an analysis of evidence based reviews of VBP and field based research that included environmental scans. The authors concluded that limited evidence relative to VBP outcomes currently exists; thus further research is needed to demonstrate improvement in patient outcomes and related cost savings. Quality should permeate an institution so that all staff strives to maintain the best outcomes for patients. In 2005, the Robert Wood Johnson Foundation funded the Quality and Safety Education for Nurses (QSEN). The goal of the project was to meet the challenge of preparing future nurses who would have the knowledge, skills, and attitudes (KSAs) necessary to continuously improve the quality and safety of the healthcare systems within which they work (Cronenwett et al., 2007). This project was 
implemented in three phases and focused on six competencies, five of which were derived from the IOM report on Health Professions Education: A Bridge to Quality (2003) and include, patient-centered care, teamwork and collaboration, evidence-based practice, quality improvement, informatics, and safety.

The AACN has incorporated quality outcomes as part of the curricula for The Essentials (AACN, 2011). Incorporating quality improvement into Master's education provides an expectation that graduate nursing students have a clear understanding of the transformations of healthcare reform. As more APNs enter the field, preventative care and leading initiatives that impact quality outcomes are increasingly becoming the focus of the APN role. It is imperative for APNs to have a clear understanding of how they can improve patient outcomes and the healthcare experience. The graduate nurse will need an astute understanding of reimbursement, quality initiatives such as VBP, and how they can impact compliance (Kennerly, 2007). There are gaps in the literature that link quality improvement efforts of APN practice to improved patient outcomes.

Kleinpell and Gawlinski (2005) discussed the use of quality indicators to demonstrate outcomes of APN practice. The study reviewed APN care of heart failure patients and the discharge instructions that patients received were evaluated. A multidisciplinary team was constructed to identify practices for improvement with heart failure discharge education. The strategies included identifying heart failure patients during shift report, daily screening of admissions, reviewing of admissions by the APN, and placing heart 
failure stickers on charts as a reminder to staff. Successful completion of discharge instructions increased from a baseline of $22 \%$ to $87 \%$ after four months. The researchers concluded that using quality indicators represents a useful way to highlight the impact of APN care.

Wolosin, Ayala, and Fulton (2012) examined how patient satisfaction predicted the HCAHPS global rating score, which in contrast to the CMS Core Measures are based entirely on patients' perception of care. This study compared the impact of nursing care with other areas on overall satisfaction. Findings suggested that facilities focusing on HCAHPS in conjunction with VBP would likely see the greatest impact by engaging nursing in care improvements. 


\section{Educational Innovation}

Getting a new idea adopted, even when it has obvious advantages, is difficult (Rogers, 2003). Rogers Diffusion of Innovation theory was used to guide the development and implementation of an educational activity for graduate nursing students on VBP. According to Rogers, an innovation is communicated through certain channels over time among the members of a social system. The rate of adoption of innovation is based on the perceptions of individuals' reaction to the innovation and the degree of adoption is dependent on the change agents' effort (Rogers). Value based purchasing is a new expanse in healthcare reimbursement and APN awareness and involvement as a change agent is paramount.

The content and objectives for the educational sessions were derived from a literature review, The Essentials of Master's Education in Nursing (AACN, 2011), and the clinical quality experience of the author. The content was delivered in one class session of a master's level Health Care Systems' course that had a course objective related to quality. The learning objectives for the class were to: define and describe VBP; identify the role that CMS Core Measures and HCAHPS play in VBP and quality care; and identify areas where APNs can impact quality improvement. The Institutional Review Board (IRB) approved this project. An informational letter was given to participants prior to a five question pretest developed by the author. The test was designed to align with the objectives, and included, five objective multiple choice questions, two of which 
specifically addressed VBP, two related to the core measures, and one specific to HCAHPS. One open ended question explored the APN role regarding VBP.

Twelve nursing students voluntarily participated in a brief presentation that included a case study derived from the literature and then completed the same five item post-test. This was followed by a question and answer period which was structured to provide participants with an opportunity to discuss these quality initiatives and to expand on how the APN could impact these areas of quality.

The mean score on the pre-test was 55 out of 100; the mean post-test score was 72 , with some improvement noted on each item for all participants. The open ended question, "Please comment on VBP and if/how it will affect your practice"- revealed some interesting responses from several students:

- $\quad$ "APNs can assist by helping lower costs and length of stay as well as improving outcomes;"

- $\quad$ "If we can continue to provide quality care then we will get back our reimbursement... helping to distinguish us as better hospitals;"

- 'Improves practice by adhering to interventions that are evidence based, therefore improving outcomes and payment".

Participants had numerous questions about VBP and exhibited excitement about the topic. The students recognized that VBP will impact their future practice. Students identified a lack of knowledge about VBP at the staff nurse level, as well as a lack of 
Page 10

understanding about the role of a quality department, the data that is collected and the relationship to outcomes. 


\section{Discussion and Recommendations}

The need to include quality improvement and safety into the curricula is evident in the Masters' Essentials. The students' enthusiasm for the topic demonstrated a readiness to incorporate this knowledge into practice. This cohort of graduate nursing students could potentially be the change agents that will bring forward what they have learned in this educational session to their practice and be the innovators of VBP. Based on this project, it is recommended that similar educational sessions be implemented with graduate nursing students, including APNs. Graduate nursing programs can drill down on the contemporary quality initiatives that will effect reimbursement and the hospital payment strategies as it relates to the APN role. The APNs with this knowledge would have a tremendous opportunity to impact quality care and improve patient outcomes as they enter the workforce. 


\section{Conclusion}

As CMS evolves from a passive payer to a prudent purchaser of quality care for their beneficiaries (CMS, 2010, page 2, para 1), the opportunity for the APN role to expand is evident. The APN has the capability to bridge quality initiatives to the delivery of exceptional care and provisions of better outcomes for patients. Quality initiatives, like evidence based guideline, should be incorporated in the assessment and care of a patient. Pay for performance has always been discussed as future expectation: that time is upon us now. The need for a provider to champion quality initiatives and increase the facilities' reimbursement potential is crucial.

Quality is coming to the forefront in healthcare institutions. Patient Protection and Affordable Care Act demands better outcomes for patients. VBP is still in its infancy and the full range of benefits has not yet been revealed. Advanced practice nurses need to be up-to-date with new initiatives. Advanced practice nurses must understand the guidelines to capitalize on better patient outcomes which in turn will potentially increase reimbursement for the hospital system. This educational innovation brought a current quality initiative to academia. Students' enthusiasm for this content indicated their interest in learning about VBP. It is essential to educate APNs about the reality of quality, and reimbursement. 
References

AHRQ Evaluating the Impact of Value-Based Purchasing: A Guide for Purchasers (2012). Retrieved from http://www.ahrq.gov/professionals/quality-patientsafety/quality- resources/value/valuebased/index.html. June 2012

American Association of Colleges of Nursing. (2011). The Essentials in Masters

Education in Nursing. Retrieved from http://www.aacn.nche.edu/educationresources/MastersEssentials11.pdf

Centers for Medicare and Medicaid Services. Medicare Fact Sheet (2010). Retrieved from http://www.cms.gov/Medicare/Medicare-Fee-for-ServicePayment/AcuteInpatientPPS/downloads/FSQ09_IPLTCH11_NPRM041910.pdf

Chassin, M. R., Loeb, J. M., Schmaltz, S. P., \& Wachter, R. M. (2010). Accountability measures - using measurement to promote quality improvement. The New England Journal of Medicine, 363(7), 683-688.

Cronenwett, L; Sherwood, G; Barnsteiner, J; Disch, J; Johnson, J; Mitchell, P; Sullivan, D T; Warren, J; (2007). Quality and safety education for nurses. Nursing Outlook, 55(2), 122-131.

Eldridge, G. N., \& Korda, H. (2011). Value-based purchasing the evidence. American Journal of Managed Care, 17(8), e310-e313.

“Medicare Program: Hospital Inpatient Value-Based Purchasing Program; Final Rule," 76 Federal Register 88 (06 May 2011), pp. 26490-26547 
HCAHPS Hospital Care Quality Information from The Consumer Perspective. (2012). Retrieved July 2012, from www.hcahpsonline.org Institute of Medicine. (1996). America's Health in Transition: Protecting and Improving Quality. Retrieved from http://www.nap.edu/openbook.php?record_id=9147 Institute of Medicine. (2001). Crossing the Quality Chasm: The IOM Health Care Qualtiy Initiative. Retrieved from http://www.iom.edu/Global/News\%20Announcements. August 2013 Institute of Medicine. (2003). Health Professions Education: A Bridge to Quality. Retrieved from http://www.iom.edu/reports/2003/health-professions-education-abridge-to-quality.aspx. July 2012

Institute of Medicine. (1999). To Err is Human: Building A Safer Health System. Retrieved from http://iom.edu/Reports/1999/To-Err-is-Human-Building-A-SaferHealth-System.aspx. September 2013

Kennerly, S. (2007). The impending reimbursement revolution: How to prepare for future APN reimbursement. Nursing Economics,25(2), 81-84.

Kleinpell, R., \& Gawlinski, A. (2005). Assessing outcomes in advanced practice nursing practice the use of quality indicators and evidence-based practice. AACN Clinical Issues, 16(1), 43-57.

Quality and Safety Education for Nurses. (n.d.). http://qsen.org/about-qsen/projectoverview/ 
Rogers, E. M. (2003). Diffusion of innovations (5th ed.). New York, NY: Free Press A Division of Simon \& Schuster, Inc.

U.S. Department of Health and Human Services. (2011). Administration Implements Affordable Care Act Provisions to Improve Care, Lower Costs [Press Release]. Retrieved from U.S. Department of Health and Human Services: www.hhs.gov Wolosin, R., Ayala, L., \& Fulton, B. R. (2012). Nursing care, inpatient satisfaction, and value-based purchasing. The Journal of Nursing Administration, 42(6), 321-325. 
